\title{
Yaş ve Döneme Özgü, İki Eşeyli Yaşam Çizelgesi: Populasyon Ekolojisi, Biyolojik Savaş ve Zararlı Yönetiminin Temeli
}

\author{
Remzi ATLIHAN ${ }^{1}$, Mehmet Salih ÖZGÖKÇE ${ }^{1}$, Hsin CHI ${ }^{2}$ \\ ${ }^{1}$ Van Yüzüncü Y1l Üniversitesi Ziraat Fakültesi, Bitki Koruma Bölümü, Van, Türkiye \\ ${ }^{2}$ Niğde Ömer Halisdemir Üniversitesi, Tarım Bilimleri ve Teknolojileri Fak., Bitki Koruma ve Teknolojileri Böl., Niğde, Türkiye \\ Öz: Yaşam çizelgeleri, çok sayıda biyolojik parametrenin (hayatta kalma, gelişme, doğurganlık, vb.) bileşik etkilerini \\ kapsamlı bir şekilde yansıttıklarından dolayı, popülasyon ekolojisi, biyolojik mücadele ve zararlı yönetimiyle ilgili \\ araştırma yapan biyologlar ve diğer araştırıcıların kullanabileceği en güçlü araçlardan biridir. Dişiye ve yaşa özgü \\ geleneksel yaşam çizelgeleri, erkek popülasyonunu ve dönem farklılaşmasını ihmal ettiği için kullanımları sıkça \\ hatalara ve yanlışlara neden olur. Bu makale yaş ve döneme özgü, iki eşeyli (two-sex) yaşam çizelgesini kullanmanın \\ nedenlerini ve avantajlarını tartışmak üzere hazırlanmıştır.
}

Anahtar kelimeler: İki eşeyli yaşam çizelgesi, Yaş-dönem, Yaşam çizelgesi

\section{Age-Stage, Two-Sex Life Table: The Basis of Population Ecology, Biological Control and Pest Management}

\begin{abstract}
Because they are capable of providing an integrated and comprehensive description of numerous biological parameters (survival, development, fecundity, etc.) of a population, life tables are one of the most powerful tools available for biologists and other researchers conducting research on population ecology, biological control, and pest management. Since the traditional female age-specific life tables ignore the male population and stage differentiation, their use often results in errors and inaccuracies. This article was prepared to discuss the reasons and advantages of using the age-stage, two-sex life table.
\end{abstract}

Keywords: Two-sex life table, Age-stage, Life table

\section{Giriş}

Zararlıların populasyon büyüklüğü, yaş dağılımı, gelişme oranı, üreme, canlılık oranı ve tüketim oranı hakkında yeterli bilgiye sahip olmak onlarla mücadelede oldukça önemlidir. Bu bilgiler olmadan, bir zararlı popülasyonunun büyüme oranını ve zararını, ya da mücadele zamanı ve kontrol uygulamalarının sayısını tahmin etmek mümkün değildir. Benzer şekilde, biyolojik savaşta, en uygun salım zamanını, salımı yapılacak doğal düşman sayısını ve salım sayısını tahmin edebilmek için doğal düşmanların populasyon büyüklüğü, yaş dağılımı, gelişme oranı, canlılık oranı ve predasyon/parazitlenme oranı hakkında bilgilere sahip olmak son derece önemlidir. Canlılık oranı, üreme ve tüketim oranı, böceklerin yaşına ve dönemine bağl1 olarak değiştiği için, basitleştirilmiş modeller (örneğin, üstel (exponential) büyüme ve lojistik büyüme) yaş dağılımını, yaşa özgü canlılık oranını, yaşa özgü tüketim oranını açıklayamamaktadır. Bu nedenle, bu modeller zararlı yönetimi ve biyolojik savaşta kullanılamazlar.

Dişiye ve yaşa özgü geleneksel yaşam çizelgeleri (Euler 1760, Lotka 1907, Lewis 1942, Leslie 1945, Birch 1948, Carey 1993) erkek popülasyonunu ve dönem farklılaşmasını (dönem farklılıkları ve geçişleri) göz ardı etmektedir. Bu modeller dönem farklılıklarını ve dönemler arası geçişi tanımlayamadığından, birçok yazar, yaşa özgü üremeyi elde etmek için "ergin yaşını" kullanmıştır. Bireyler arasında gelişme oranlarındaki farklılıklar nedeniyle, ergin dişiler farklı yaşlarda ortaya çıkmaktadır. Bu durumda "ergin yaşını" kullanmak, yaşam çizelgesi analizinde ve yaşam çizelgelerine bağlı zararlı yönetimi uygulamalarında önemli hatalara neden olacaktır. Ayrıca, dişiye ve yaşa özgü yaşam çizelgeleri, hesaplamalarda erkek popülasyonunu ihmal ettiği için, üremenin hesaplanmasına sadece "dişi yavrular" dahil edilebilmektedir. Birçok bilim adamı, "dişi yumurtaları" veya "dişi yavruları" hesaplamak için sabit bir cinsiyet oranı (örn., 1:1) kullanmaktadır. Bu varsayım, veri analizinde hatalarla sonuçlanmaktadır. Bu nedenle, dişiye ve yaşa özgü yaşam çizelgesi zararlı yönetimine beklenen katkıyı sağlayamamıştır.

Chi ve Liu (1985), dönem farklılaşmasını ayrıntılı olarak ele alan ve her iki cinsiyeti de hesaplamalara dahil eden yaş ve döneme özgü, iki eşeyli (two-sex) yaşam çizelgesini geliştirmiştir. Ayrıca, bilim adamlarının yaşam çizelgesi verilerini etkin ve kolaylıkla analiz etmelerine yardımcı olmak için, ücretsiz bir yazılım olan TWOSEX-MSChart 
programı da Chi ve Yang (2003) tarafından kullanıma sunulmuş ve sürekli güncellenerek günümüze dek gelmiştir. Bu arada, pek çok bilim insanı zamanla dişiye ve yaşa özgü yaşam çizelgeleri ile ilgili sorunları fark etmiştir. Nitekim, son yirmi yılda yaş ve döneme özgü, iki eşeyli yaşam çizelgesi prensibine dayalı bilimsel yayınların sayısı çarpıcı bir şekilde artmıştır. Chi (1990), yaşam çizelgesi sonuçlarının pratiğe aktarılması ve zararlılarla mücadelede zamanlamanın belirlenmesine katkıda bulunmak üzere yaş ve döneme özgü, iki eşeyli yaşam çizelgesini kullanarak TIMING-MSChart yazılımını geliştirmiş ve ücretsiz kullanıma sunmuştur. Ayrıca Chi ve Yang (2003) ve Chi ve Su (2006) predator ve parazitoidler ile yapılan çalışmalarda kullanılmak üzere yaş ve döneme özgü, iki eșeyli yaşam çizelgesine dayalı olarak CONSUME-MSChart programını geliştirmiş ve bilim insanlarının kullanımına sunmuşlardır.

Bu makale, Türkiye'de daha fazla sayıda bilim insanının ekolojik çalışmalar, zararlı yönetimi ve av-avcı ilişkilerine dair çalışmalarda yaş ve döneme özgü iki eşeyli yaşam çizelgesinden yararlanmasına olanak sağlamak üzere hazırlanmıştır.

Yaş ve döneme özgü, iki eşeyli yaşam çizelgesi kullanmanın nedenleri ve avantajları

1. Yaş ve döneme özgü, iki eşeyli yaşam çizelgesi, dönem farklılaşmasını tam olarak tanımlayabilir. Dönem farklılaşması böcek ve akarlara özgü bir özellik olup, farklı dönemlerdeki bireyler fizyoloji, davranış, direnç, adaptasyon vb. özellikler bakımından değişiklikler gösterirler. Bu nedenle, her türlü araştırma için (ekoloji, fizyoloji, toksikoloji, zararlı yönetimi vb.) dönem farklılaşmasının uygun ve doğru bir şekilde tanımlanması çok önemlidir. İki eşeyli yaşam çizelgesinde, yaş ve döneme özgü canlılık oranı $\left(s_{x j}\right)$, yeni doğmuş bir bireyin $x$ yaşına ve $j$ dönemine kadar yaşayabilme olasılığını gösterir ve dönem çakışmaları $s_{x j}$ eğrilerinde gözlemlenebilir. Oysa, dişiye ve yaşa özgü yaşam çizelgesi bu konuda yetersiz kalmaktadır.

2. Yaş ve döneme özgü, iki eşeyli yaşam çizelgesi hem her iki eşeyi hem de ergin öncesi dönemde ölen bireyleri hesaba katar. Örneğin, erkek uğurböceği bireyleri dişi bireyler gibi avlanmakta ve yaprakbitlerini öldürmektedir. Erkek bireylerin katkısının ihmali, hatalara ve biyolojik mücadele stratejilerinin planlanmasında yanlışlıklara yol açabilecektir. Benzer şekilde, lahana yaprak güvesi ve patates böceğinin erkekleri konukçularında zararlara neden olabilmektedir. Erkek bireylerin neden olduğu zararı görmezden gelmek, üründeki zararın doğru tahmin edilmesinde ve zararlı yönetiminde hatalara neden olabilecektir.

3. Eşey oranı böcek ve akar popülasyonları için oldukça önemlidir. Yaşam çizelgesi analizinde eşey oranı göz ardı edilirse, ulaşlacak sonuçlar doğru olmayacaktır. TWOSEX-MSChart programında, eşey oranının etkisi bootstrap tekniği kullanılarak hesaba katılır. Diş̧iye ve yaşa özgü geleneksel yaşam çizelgesinde, erkek bireylere ait veriler hesaplamalara dahil edilmediğinden, cinsiyet oranının etkisi de göz ardı edilmiş olur. Oysa zararlılarla mücadelede eşey oranına dair bilgiler oldukça önem arz eder. Örneğin, steril böcek tekniği (sterile insect technique, SIT)'nde ve erkek imha tekniği (male annihilation technique)'nde, eșey oranının etkisi mutlak olarak dikkate alınmalıdır. Bu nedenle bu tür çalışmalar için yaş ve döneme özgü, iki eşeyli yaşam çizelgesi kullanılması büyük yararlar sağlamaktadır (Chang ve ark. 2015).

4. Bootstrap tekniği çok zaman gerektirdiğinden, bilgisayarlar popüler ve yaygın olmadan önce birçok araştırmacı yaşam çizelgesi parametrelerini karşılaştırmak için Jackknife tekniğini kullanmaktaydı. Bu teknikte istenilen yaşam çizelgesi parametresi kullanılan tekerrür sayısı kadar üretilebilmektedir. Ancak, günümüzde bilgisayarlar tüm bilim adamları için kolayca erişilebilir durumdadır ve ayrıca Huang and Chi (2012), Jackknife tekniğinin yaşam çizelgesi analizinde kullanılmaması gerektiğini kanıtlamıştır. TWOSEX-MSChart programında 100.000 bootstrap önerilmekte olup, sonuçlar "Merkezi Limit Teoremi” ile uyumludur. Özgökçe ve ark (2018) rastgele elde edilen bootstrap sonuçlarının normal dağılım olarak sıralanabileceğini göstermiş ve ayrıca birçok istatistikçi bootstrap tekniğinin avantajlarına dikkat çekmiştir.

5. Yaş ve döneme özgü, iki eşeyli yaşam çizelgesi eşeyler arasındaki farklılıkları göstermektedir. TWOSEX-MSChart programı kullanılarak eșeyler arasındaki gelişme oranı, canlılık oranı, yaşam süresi ve beklenen yaşam süresi farklılıklarını tespit etmek oldukça kolaydır.

6. Yaş ve döneme özgü, iki eşeyli yaşam çizelgesi kullanılarak ortalama üreme $(F)$ ve net üreme gücü $\left(R_{0}\right)$ arasındaki ilişki her zaman doğru olarak elde edilir. Chi (1988) bu ilişkiyi aşağıdaki denklem ile kanıtlamıştır:

$$
R_{0}=\frac{N_{f}}{N} F
$$

$N$, yaşam tablosu çalışmasında kullanılan bireylerin sayısi; $N_{f}, N$ 'deki ergin dişilerin sayısıdır. Bu ilişki, hem tek başına dişilerden oluşan populasyonlar, hem de iki eşeyli popülasyonlar için geçerlidir.

7. Bir predatörün/avcının predasyon oranı veya bir zararının tüketim oranı, yaş ve döneme özgü, iki eşeyli yaşam 
çizelgesine dayalı olarak analiz edildiğinde predasyon oranı ve tüketim oranı bakımından dönemler arasındaki değişkenliği ortaya çıkarmak mümkün olmaktadır. Predasyon oranı ve tüketim oranı yaş ve döneme bağlı olarak değiştiği için, av-avcı ya da konukçu-zararlı ilişkisinin yaş ve döneme özgü, iki eşeyli yaşam çizelgesine dayalı olarak incelenmesi gerekmektedir. CONSUME-MSChart programı, kullanıcıların yaşam çizelgesi çalışmasını predasyon ya da tüketim oranı çalışmasıyla ilişkilendirmelerine yardımcı olur.

8. Veri düzenlemeden kaynaklanan hatalardan kaçınmak ve yaşam çizelgesi ile predasyon oranı analizini doğru bir şekilde ilişkilendirmek için, TWOSEX programı CONSUME programı için 100.000 bootstrap örneği üreterek kaydeder. Net üreme oranından $\left(R_{0}\right)$ net predasyon oranına $\left(C_{0}\right)$ dönüşüm (transformasyon) oranı $\left(Q_{p}\right)$ sadece bu yolla doğru olarak elde edilebilir.

9. TWOSEX programı kullanılarak, “ergin preovipozisyon (üreme öncesi) dönemi” ve “toplam preovipozisyon dönemi” arasındaki fark ortaya çıkarılabilir. Çoğu entomolog "preovipozisyon periyodunu” ergin çıkışı ile ilk üreme arasındaki süre olarak tanımlamaktadır. Yaş ve döneme özgü, iki eşeyli yaşam çizelgesinde, hem "ergin preovipozisyon periyodu (adult preoviposition period, APOP)" (ergin çıkışı ile ilk üreme arasındaki süre) hem de "toplam preovipozisyon periyodu (total preoviposition period, TPOP)" (doğumdan ilk üremeye kadar geçen süre) hesaplanmaktadır. Lewontin (1965) ilk üreme yaşının kalıtsal üreme oranına etkisinin önemli olduğuna işaret etmiştir. APOP, ergin öncesi süreyi göz ardı ettiği için, ilk üreme yaşının popülasyonun büyümesine etkisini gösteremez. Bunun aksine, TPOP ilk üreme yaşının popülasyon artış oranı üzerindeki etkisini göstermek için kullanılabilir. Bu, TPOP ile üreme değeri $\left(v_{x j}\right)$ tepe noktasının oluştuğu yaş arasındaki ilişkide gözlenebilir. Yumurta dönemi olmayan böcekler için APOP, APRP (adult pre-reproductive period, ergine ait üreme öncesi dönem) ile TPOP ise TPRP (total pre-reproductive period, toplam üreme öncesi dönem) ile değiştirilebilir.

10. Popülasyon artışındaki değişkenliği ortaya koymak için, gelişme oranı, canlılık oranı, üreme ve cinsiyet oranındaki değişmeleri iyi anlamak gerekir. Tüm bu faktörlerdeki değişimleri içerecek şekilde TWOSEX programı, bootstrap örneklerinin 0.025 ve 0.975 yüzdeliklerini temel alan yaşam çizelgesi oluşturur. Bu yeni bir konsepttir ve popülasyon artışındaki belirsizliğin ölçüsünü (güven aralığını) yansıtmak için kullanılabilir. Bu konsept aynı zamanda predasyon potansiyelinin belirsizliğini ortaya çıkarmak için de kullanılabilmektedir.

11. Zararlı ve predatör popülasyonlarındaki dönemlerin yaş dağılımı zararlı yönetiminde önemli olduğu için TWOSEX programı yaşam çizelgesi verilerini TIMING programı için düzenler. Kullanıcılar yaşam çizelgesi verilerine dayalı olarak popülasyon artışını simüle edebilir ve örneğin, simülasyonda pestisit uygulamasından dolayı her bir dönemde ortaya çıkan ölüm oranını hesaplayabilirler.

12. TWOSEX programı hem ovipozisyon periyodunu (üreme süresi) hem de ovipozisyon günlerini hesaplar. Çoğu entomolog "ovipozisyon periyodunu" üremenin başlamasından son bulmasına kadar geçen süre olarak tanımlar. Aslında, birçok böcek oogeneze (yumurta oluşma sürecine) bağlı olarak periyodik bir şekilde az veya çok yumurta üretir. Ovipozisyon süresinin uzunluğu, üreme potansiyelinin göstergesi olarak kullanılamaz. TWOSEX programı, bir böceğin yumurta bıraktığı/ürediği gün toplamını (ovipozisyon günleri) hesaplar. Kullanıcılar, ovipozisyon dönemiyle ovipozisyon günlerini karşılaştırabilir veya üreme biçimini ortaya çıkarmak için ovipozisyon günlerinin ovipozisyon dönemine oranını hesaplayabilirler.

13. TWOSEX programları, $N_{f} / N, N_{m} / N, N_{n} / N$, ve $N_{m} / N_{f}$ oranlarına dair istatistikleri sunmaktadır. Burada $N$, denemede kullanılan birey sayısı; $N_{f}, N^{\prime}$ den ortaya çıkan ergin dişilerin sayısı; $N_{m}$, ergin erkeklerin sayısı; $N_{n}$, ergin öncesi dönemde ölen bireylerin sayısıdır. Bunlar ergin dişi ve erkeklerin oranı ile ergin öncesi ölüm oranını göstermektedir. Bu seçenekler tek bir dişi:erkek oranını kullanmaktan çok daha yararlıdır.

14. İki farklı biyolojik mücadele etmeninin karşılaştırılmasında, predasyon oranını veya populayon artış oranını ayrı ayrı karşılaştırmak doğru değildir. Chi ve ark. (2011) ve Yu ve ark (2013) TWOSEX ve CONSUME programlarını birbirleriyle ilişkilendirmiş ve predasyon potansiyellerinin karşılaştırılması için predasyon oranı sınırını tanımlamıştır.

15. Biyolojik mücadele programlarında kullanılacak etmenlerin kitle halinde üretilmesi önemli bir iştir. TWOSEX programı, üretim ve ekipman maliyetlerine bağlı olarak kitle üretimi, üretim miktarını ve salım için uygun yaş ve dönemi analiz etmede kullanılabilir (Chi ve Getz 1988, Yu ve ark. 2018).

16. Yaşam çizelgesi çok sayıda veri üretir. Bu veriler incelenen her bir bireyin gelişme, canlılık oranı, üreme gibi tüm faktörleri ile ve birbirleriyle yakından ilişkilidir. Örneğin, yaşam çizelgesi analizinde, üreme eğrisini $\left(m_{x}\right)$ göz ardı ederek canlı kalma eğrisini $\left(l_{x}\right)$ analiz etmek uygun değildir. Atlihan ve ark. (2017), canlı kalma oranını Weibull'a uydurmanın dikkatle yapılması gerektiğine işaret etmiştir. Bununla birlikte, birçok bilim insanı sadece canlı kalma eğrisini $\left(l_{x}\right)$ Weibull fonksiyonuna veya sadece üreme eğrisini $\left(m_{x}\right)$ Enkegaard modeline uydurmuşlardır, ama bu parametrelerin bileşik etkilerini tartışmamışlardır. 
Yukarıda sıralananlar, yaş ve döneme özgü iki eşeyli yaşam çizelgesinin kullanılmasının sadece bazı önemli avantajlarını göstermektedir. TWOSEX programı ayrıca grafik ve tablo hazırlamak için ve daha fazla istatistiksel analiz yapmak için çok sayıda veri dosyası sunmaktadır.

\section{Sonuç ve Öneriler}

Yaşam çizelgesi sadece ekolojik araştırmalar ve zararlı yönetimi için önemli bir araç değildir. Günümüzde fizyolojik ve biyokimyasal araştırmalarda da yaygın olarak kullanılmaktadır. Örneğin, toksikolojik çalışmalarda, araştırmacılar sadece dirençli ırkların canlı kalma veya üremesine odaklanırsa, dirençli ırkların popülasyon büyümesi hakkında kapsamlı bir bilgiye ulaşmaları mümkün olmaz. Popülasyon artış oranını anlamak ve popülasyon artışını simüle etmek ancak yaşam çizelgesi ile mümkündür. Benzer şekilde böcek simbiyontları üzerinde çalışan entomologlar için, simbiyontları uzaklaştırmanın, böcek popülasyonlarının canlılığı, gelişmesi ve doğurganlığı üzerindeki etkisinin anlaşılması da gerekmektedir. Bu tür sonuçlara ulaşmak için de yaşam çizelgesi kullanmak gerekmektedir. Yaş ve döneme özgü iki eşeyli yaşam çizelgesi teorisi, biyolojik verileri büyük bir veri seti olarak ele alır. Bootstrap tekniği kullanılarak, herhangi bir böceğin tüm verileri entegre edilir. TWOSEX-MSChart programı kullanımı kolay olmasına ve farklı ülkelerden kullanıcılar tarafından yaygın olarak kullanılmasına rağmen, kullanıcıların yaş ve döneme özgü iki eşeyli yaşam çizelgesi teorisini anlamaları oldukça önemlidir. Ancak o zaman doğru yorum ve uygulama yapılabilir.

\section{Kaynaklar}

Atlihan R, Polat-Akköprü E, Özgökçe MS, Kasap İ, Chi H (2017). Population growth of Dysaphis pyri (Hemiptera: Aphididae) on different pear cultivars with discussion on curve fitting in life table studies. J. Econ. Entomol. 110(4): 1890-1898. doi: 10.1093/jee/tox174.

Birch LC (1948). The intrinsic rate of natural increase of an insect population. J. Anim. Ecol. 17: 15-26.

Carey JR (1993). Applied demography for biologists with special emphasis on insects. Oxford University Press, Inc. New York, NY.

Chang C, Huang CY, Dai SM, Atlihan R, Chi H (2016). Genetically engineered ricin suppresses Bactrocera dorsalis (Diptera: Tephritidae) based on demographic analysis of group-reared life table. J. Econ. Entomol. 109(3): 987-992.

Chi H, Liu H (1985). Two new methods for the study of insect population ecology. Bull. Inst. Zool., Acad. Sin. 24: 225-240.

Chi H (1988). Life-table analysis incorporating both sexes and variable development rates among individuals. Environ. Entomol. 17: 26-34.

Chi H (2018a) TWOSEX-MSChart: a computer program for the age-stage, two-sex life table analysis. National Chung Hsing University, Taichung, Taiwan. (http://140.120.197.173/Ecology/Download/Twosex-MSChart.rar).

Chi H (2018b). CONSUME-MSChart: A computer program for the age-stage, two-sex consumption rate analysis. National Chung Hsing University, Taichung, Taiwan (http://140.120.197.173/ecology/).

Chi H (2018c). Timing-MSChart: A computer program for the population projection based on age-stage, two-sex life table. National Chung Hsing University, Taichung, Taiwan (http://140.120.197.173/ecology/).

Chi H, Getz WM (1988). Mass rearing and harvesting based on an age-stage, two-sex life table: a potato tuberworm (Lepidoptera: Gelechiidae) case study. Environ. Entomol. 17:18-25. DOI: https://doi.org/10.1093/ee/17.1.18

Chi H (1990). Timing of control based on the stage structure of pest populations: a simulation approach. J. Econ. Entomol. 83: 1143-1150.

Chi H, Yang TC (2003). Two-sex life table and predation rate of Propylaea japonica Thunberg (Coleoptera: Coccinellidae) fed on Myzus persicae (Sulzer) (Homoptera: Aphididae). Environ. Entomol. 32(2): 327-333.

Chi H, Su HY (2006). Age-stage, two-sex life tables of Aphidius gifuensis (Ashmead) (Hymenoptera: Braconidae) and its host Myzus persicae (Sulzer) (Homoptera: Aphididae) with mathematical proof of the relationship between female fecundity and the net reproductive rate. Environ. Entomol. 35(1): 10-21.

Chi H, Mou DF, Allahyari H, Yu JZ, Huang YB, Yang TC, Farhadi R, Gholizadeh M (2011). Finite predation rate: a novel parameter for the quantitative measurement of predation potential of predator at population level. In: Nature Precedings. Available from: <http://hdl.handle.net/10101/npre.2011.6651.1>.

Efron B, Tibshirani RJ (1993). An Introduction to the Bootstrap. Chapman \& Hall, New York, NY.

Euler L (1760). “Recherches généales sur la mortalité et la multiplication du genre humain,” Histoire de l’Académie Royale des Sciences et Belles-Lettres, année 1760, pp. 144-164. Berlin, (1767). [Translated by Nathan and Beatrice Keyfitz (1970) as "A general investigation into the mortality and multiplication of the human species" published in Theoretical Population Biology 1, 307-314.]

Huang YB, Chi H (2013). Life tables of Bactrocera cucurbitae (Diptera: Tephritidae): with an invalidation of the jackknife technique. J. Appl. Entomol. 137: 327-339.

Leslie PH (1945). On the use of matrices in certain population mathematics. Biometrika 33: 183-212.

Lewis EG (1942). On the generation and growth of a population. Sankhya 6: 93-96.

Lewontin RC (1965). Selection for colonizing ability. The Genetics of Colonizing Species (eds. H. G. Baker and G. 
L. Stebbins.) pp. 77-94. Academic Press, San Diego, CA.

Lotka AJ (1907). Studies on the mode of growth of material aggregates. Am. J. Sci. 24:199-216.

Özgökçe MS, Chi H, Atlıhan R, Kara H (2018). Demography and population projection of Myzus persicae (Sulz.) (Hemiptera: Aphididae) on five pepper (Capsicum annuum L.) cultivars. Phytoparasitica 46: 153-167.

Yu JZ, Chi H, Chen BH (2013). Comparison of the life tables and predation rates of Harmonia dimidiata (F.) (Coleoptera: Coccinellidae) fed on Aphis gossypii Glover (Hemiptera: Aphididae) at different temperatures. Biol. Control 64: 1-9.

Yu JZ, Chen BH, Güncan A, Atlıhan R, Gökçe A, Smith CL, Gümüş E, Chi H (2018). Demography and mass-rearing Harmonia dimidiata (Coleoptera: Coccinellidae) using Aphis gossypii (Hemiptera: Aphididae) and eggs of Bactrocera dorsalis (Diptera: Tephritidae). J. Econ. Entomol. 111: 595-602. doi: 10.1093/jee/toy03 